\title{
Analysis of Spatial and Seasonal Differences in the Diurnal Rainfall Cycle over Sumatera Revealed by 17-Year TRMM 3B42 Dataset
}

\author{
Abd. Rahman As-syakur ${ }^{1,5}$, Keiji Imaoka, ${ }^{2,3}$, Kakuji Ogawara ${ }^{3}$, Manabu D. Yamanaka ${ }^{4}$, \\ Tasuku Tanaka ${ }^{5}$, Yuji Kashino ${ }^{6}$, I Wayan Nuarsa ${ }^{7}$, and Takahiro Osawa ${ }^{3,5}$ \\ ${ }^{1}$ Marine Science Department, Faculty of Marine and Fisheries, Udayana University, Bali, Indonesia \\ ${ }^{2}$ Organization for Academic Information, Media and Information Technology Center, \\ Yamaguchi University, Ube, Japan \\ ${ }^{3}$ Graduate School of Sciences and Technology for Innovation, Yamaguchi University, Ube, Japan \\ ${ }^{4}$ Research Institute for Humanity and Nature, Kyoto, Japan \\ ${ }^{5}$ Center for Remote Sensing and Ocean Science (CReSOS), Udayana University, Bali, Indonesia \\ ${ }^{6}$ Department of Fishery Science and Technology, National Fisheries University, Shimonoseki, Japan \\ ${ }^{7}$ Center for Environmental Studies (PPLH), Udayana University, Bali, Indonesia
}

\begin{abstract}
We analyzed 3-hourly Tropical Rainfall Measuring Mission multi-satellite analysis (TRMM 3B42) version-7 data for the 17year period 1998-2014 to investigate seasonal and geographic characteristics of the diurnal rainfall cycle (DRC) over Sumatera, Indonesia. Dividing Sumatera into north, central, and south regions approximately perpendicular to the west coast, we point out for the first time early-afternoon initiation of daily rainfall not only in the Barisan Mountains but also in the east-coastal small islands (ECSIs) such as Bangka and Belitung. Westward and eastward migrations of rainfall areas from the Barisan Mountains are varied with seasons and regions, with the most remarkable being westward during September-October-November (SON) in the central region and the least remarkable occurring during JuneJuly-August (JJA) in the southern region. In the central region, the DRC reaches a distance of $\sim 700 \mathrm{~km}$ off the west coast during SON and of only $200 \mathrm{~km}$ during March-April-May (MAM). The other westward migrations from the ECSIs in the central and southern regions (except for JJA) have been confirmed by 5-year hourly Multi-functional Transport Satellite-1R (MTSAT-1R) cloud-top data. The results shown in this paper suggest that the rainfall distribution with respect to coastal distance, varying geographically and seasonally.

(Citation: As-syakur, A. R., K. Imaoka, K. Ogawara, M. D. Yamanaka, T. Tanaka, Y. Kashino, I. W. Nuarsa, and T. Osawa, 2019: Analysis of spatial and seasonal differences in the diurnal rainfall cycle over Sumatera revealed by 17-year TRMM 3B42 dataset. SOLA, 15, 216-221, doi:10.2151/sola.2019-039.)
\end{abstract}

\section{Introduction}

One of the most dominant variations in the convective activity over the Indonesian maritime continent (IMC) is the diurnal rainfall cycle (DRC) (Yamanaka 2016). It is generated mainly by differences between the heating of the land and sea surfaces, and the rainfall characteristics are closely related to the land-sea distribution, the terrain, and associated local circulation systems. Among many islands in the IMC, Sumatera is a cross-equatorial island located in the westernmost region of the IMC and bordering the Indian Ocean. The island is surrounded by more than 2500 smaller islands, and the Barisan Mountains, with altitudes of 2000-3800 $\mathrm{m}$, run along the west coast and divide the island into its eastern and western portions (Fig. 1). Because of its unique location and geography, Sumatera is an island that is ideally situated in the

Corresponding author: Abd. Rahman As-syakur, Marine Science Department, Faculty of Marine and Fisheries, Udayana University, Bukit Jimbaran Campus, Bali, 80361 Indonesia. E-mail:assyakur@unud.ac.id.

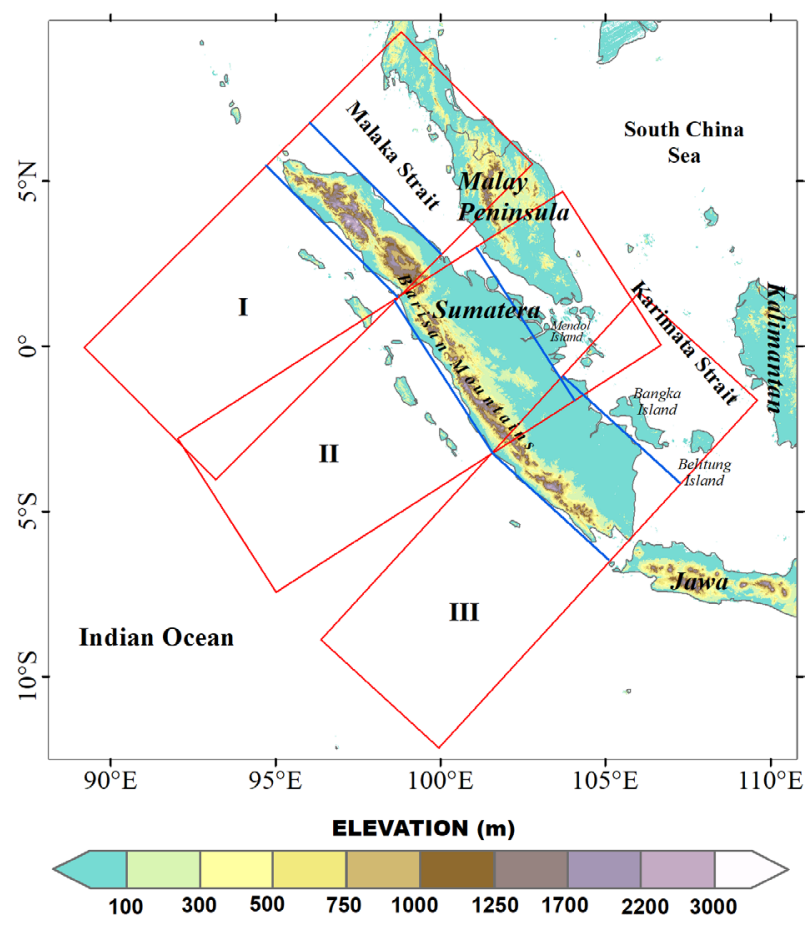

Fig. 1. Study area and topography. Three red boxes represent north (Box I), central (Box II), and south (Box III) Sumatera regions for analyzing regional differences. Blue lines indicate approximate coastline for land definition in each box.

IMC with respect to investigating the DRC and its migration. It has been well documented in previous studies (e.g., Mori et al. 2004; Sakurai et al. 2005; Wu et al. 2009) that the DRC begins by generating convections in the mountainous areas in the afternoon and tends to produce the maximum rainfall in early evening over land. The rainfall peak migrates toward the coast around midnight and finally moves offshore in early morning. That pattern is roughly the same over other large islands and adjacent regions such as Kalimantan (Ichikawa and Yasunari 2006) and Indochina (Takahashi et al. 2016) with differences being due to different local orography.

Rainfall characteristics over Sumatera are influenced also by intraseasonal, seasonal (monsoon), and interannual variations (Hamada et al. 2002; Chang et al. 2005; As-syakur et al. 2016). Previous studies have concerned mainly the features of seasonal 
variability of DRCs over the region. Yanase et al. (2017) observed the diurnal zonal migration and its seasonality from 15 years of Tropical Rainfall Measuring Mission (TRMM) Precipitation Radar (PR) and 3B42 data, but only in the southern part of Sumatera. Furthermore, Sakurai et al. (2005) investigated the seasonal differences in the migration of diurnal cloud systems over Sumatera by using 1-year of blackbody-temperature data from the Geostationary Meteorological Satellite (GMS). Their study reported that the appearance latitude of eastward cloud migration varied seasonally with the north-south displacement of the Intertropical Convergence Zone (ITCZ), while westward cloud migration appeared over the entire island during virtually all seasons.

It is still worth studying the seasonal and latitudinal changes in the diurnal rainfall migration cycle over Sumatera using data from much-longer periods. Long-term data obtained with spatiotemporally discontinuous TRMM observations can provide averaged features of the DRC for different seasons and latitudes (Mori et al. 2004; Hirose et al. 2008; Yanase et al. 2017). Our primary objective in this study has been to describe spatial and seasonal differences in the DRCs over Sumatera using long-term (17-year) 3-hourly TRMM 3B42 data.

\section{Data and method}

We used TRMM 3B42v7 data processed by TRMM MultiSatellite Precipitation Analysis (TMPA), which combines precipitation estimates from multiple satellites and from gauge analyses (where feasible) at fine scales $\left(0.25^{\circ} \times 0.25^{\circ}\right.$ and 3 -hourly) (Huffman et al. 2007). The observation period spans January 1998 through December 2014.

Our research has focused on Sumatera and the surrounding area (Fig. 1). Three cross-sectional boxes (I to III), whose long sides are roughly normal to the west coast, were defined to analyze the regional differences in the diurnal variation over the northern, central, and southern regions of Sumatera.

We divide a year into the four seasons: December-JanuaryFebruary (DJF), March-April-May (MAM), June-July-August (JJA), and September-October-November (SON). DJF and JJA seasons represent the peak of the northwest and southeast monsoon, respectively, while the MAM and SON represent monsoon transitions (Aldrian and Susanto 2003). Rainfall rates were extracted from TRMM 3B42 and unconditionally (including rain-free grids) spatially and temporally averaged over $0.25^{\circ} \times 0.25^{\circ}$ grids using 3-hourly local time bins, seasons, and regions. Each timeaveraged value of 3-hourly rainfall rates is centered in the middle of each 3-hour period. For instance, the 1200 UTC (Coordinated Universal Time) rainfall rate represents the average value between 1030 and 1330 UTC. For all figures presented in this paper, the western Indonesian local time was used as the standard time (UTC $+7 \mathrm{~h}$, correct at $105^{\circ} \mathrm{E}$ ) and denoted by LT. For instance, the rainfall rate corresponding to $01 \mathrm{LT}$ on the current day is equivalent to 18 UTC the previous day.

In order to illustrate the tendency of DRC migration over Sumatera in each region and season, we used a Hovmöller diagram to capture the propagation along with the temporal evolution. To measure the distance that the rainfall signals reach over the western sea, we used threshold rainfall rates $>0.5 \mathrm{~mm} \mathrm{~h}^{-1}$, and the distance of migration was calculated from the western coastline (Fig. 1). We examined the validity of the migration analysis by using the Multifunctional Transport Satellite-1R (MTSAT-1R) data from July 2005 through June 2010, with hourly temporal continuity and $0.04^{\circ}$ spatial resolution. The occurrence frequency of tall clouds with the cloud-top temperature less than $230 \mathrm{~K}$ was computed, according to the method by Sakurai et al. (2005) who used GMS (the predecessor of MTSAT).

\section{Results}

Figure 2a presents the spatial distribution of the average rainfall rate by season. During DJF, the heaviest rainfall was detected over the southern region, particularly over the sea in this area. In MAM, the rainfall rate begins to decline everywhere. This feature is especially notable over the sea surrounding the southern region, and the rainfall rates tend to be higher over land in the southern region and over the western ocean in the central and northern regions. In JJA, the rainfall rates are the lowest over land and the eastern sea, and they tend to increase over the western sea. During SON, rainfall rates off the central west coast appear to increase more than in other areas.

The DRC averaged over 17 years for each season is presented in Fig. 2b. The amplitude of the DRC displayed large north-south and seasonal differences, whereas the phase differences were not distinct. In all seasons, rainfall from sunrise until noon (07 and 10 LT) was distributed almost entirely over the seas surrounding the Sumatera main island and many smaller islands off the west and east coasts of the main island. During early afternoon (13 LT) in all seasons except JJA, the highest rainfall rate was observed on east-coastal small islands (ECSIs), such as Bangka and Belitung in the south region and Mendol in the central region (Fig. 1), as well as along the Barisan Mountains. In the afternoon (16 LT), rainfall over land continued to increase and began to spread toward the middle of the mainland (eastern part of the mountains), while the rainfall over the ECSIs began to decrease. On the west side of Sumatera, the peak rainfall appeared on land along the coast during the early evening, then migrated westward and eastward, weakening just before midnight (22 LT) as the system moved offshore. In northern Sumatera along the Malaka Strait, rainfall migrating eastward generally began around midnight, which is later than the westward migration observed on the west coast. After midnight ( $01 \mathrm{LT}$ ), the rainfall tended to weaken over the entire island of Sumatera and was then dispersed over the surrounding seas.

It is possible to confirm those rainfall migration patterns using Hovmöller diagrams (Fig. 3) for time-coastal distance crosssections averaged along the coastal direction for boxes I-III shown in Fig. 1. Both eastward and westward rainfall migrations from the Barisan Mountains were observed except during JJA. Those migrations were particularly noticeable during SON in the northern and central regions (I and II) and during DJF in the southern region (III). During JJA, the eastward migration pattern was not clearly observable in the central region and appeared to be virtually nonexistent over the southern region. During SON over the open ocean off the west coast in the central region, the westward migration of rainfall (higher than threshold rainfall rates of $0.5 \mathrm{~mm} \mathrm{~h}^{-1}$ ) generated on the previous day was at about 700 $\mathrm{km}$ from the coastline at $16 \mathrm{LT}$. At the same time, a new rainfall system had been generated over the Barisan Mountains. During DJF, MAM, and JJA in the central region, the westward migration reached only $\sim 350, \sim 200$, and $\sim 500 \mathrm{~km}$ from the coastline, respectively. In the northern region, the westward migration reached $\sim 250$ and $\sim 500 \mathrm{~km}$ during JJA and SON, respectively, and $200 \mathrm{~km}$ during both DJF and MAM. Meanwhile, the westward migration in the southern region reached $\sim 350$ and $\sim 250 \mathrm{~km}$ during DJF and $\mathrm{SON}$, respectively, and only $\sim 150 \mathrm{~km}$ during both MAM and JJA.

\section{Discussions and conclusion}

\subsection{Initiation of convection in Barisan Mountains and eastern islands}

Previous studies had indicated that the rainfall on land is initiated along the Barisan Mountains and then migrates to the east and west (e.g., Mori et al. 2004). However, the present study revealed that early-afternoon rainfall peaks also appeared on the ECSIs (Fig. 2b), such as Bangka and Belitung Islands in the southern region (appearing most clearly) and Mendol Island in the central region. At 13 LT, these peaks were clearly separated from the Sumatera main island, although the shortest distance is less than the horizontal resolution $\left(0.25^{\circ}\right)$. Rainfall peaks' initiation in the ECSIs were also confirmed by analyzing the MTSAT-1R data for the period July 2005 to June 2010, with a higher time resolution (hourly) compared to that of the TRMM 3B42 data (3- 
a)

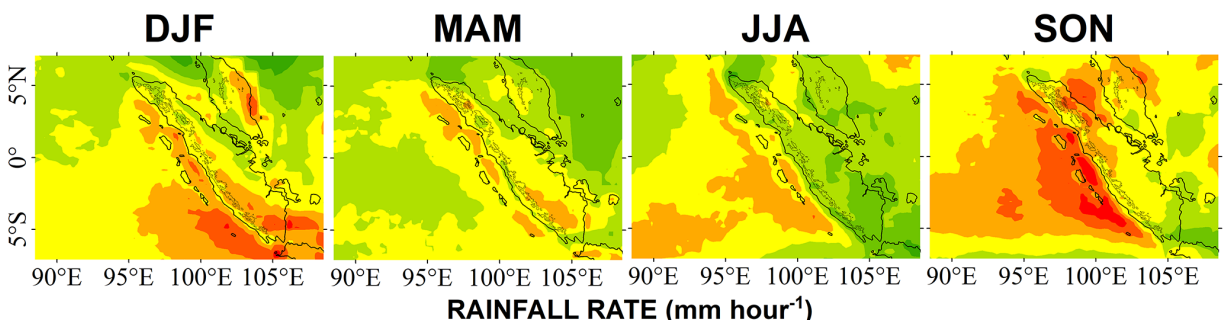

RAINFALL RATE (mm hour ${ }^{-1}$ )

b)

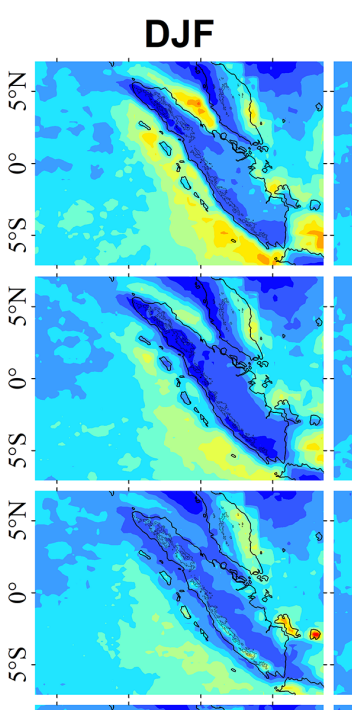

$\begin{array}{llllll}0.1 & 0.2 & 0.3 & 0.4 & 0.5 & 0.6\end{array}$
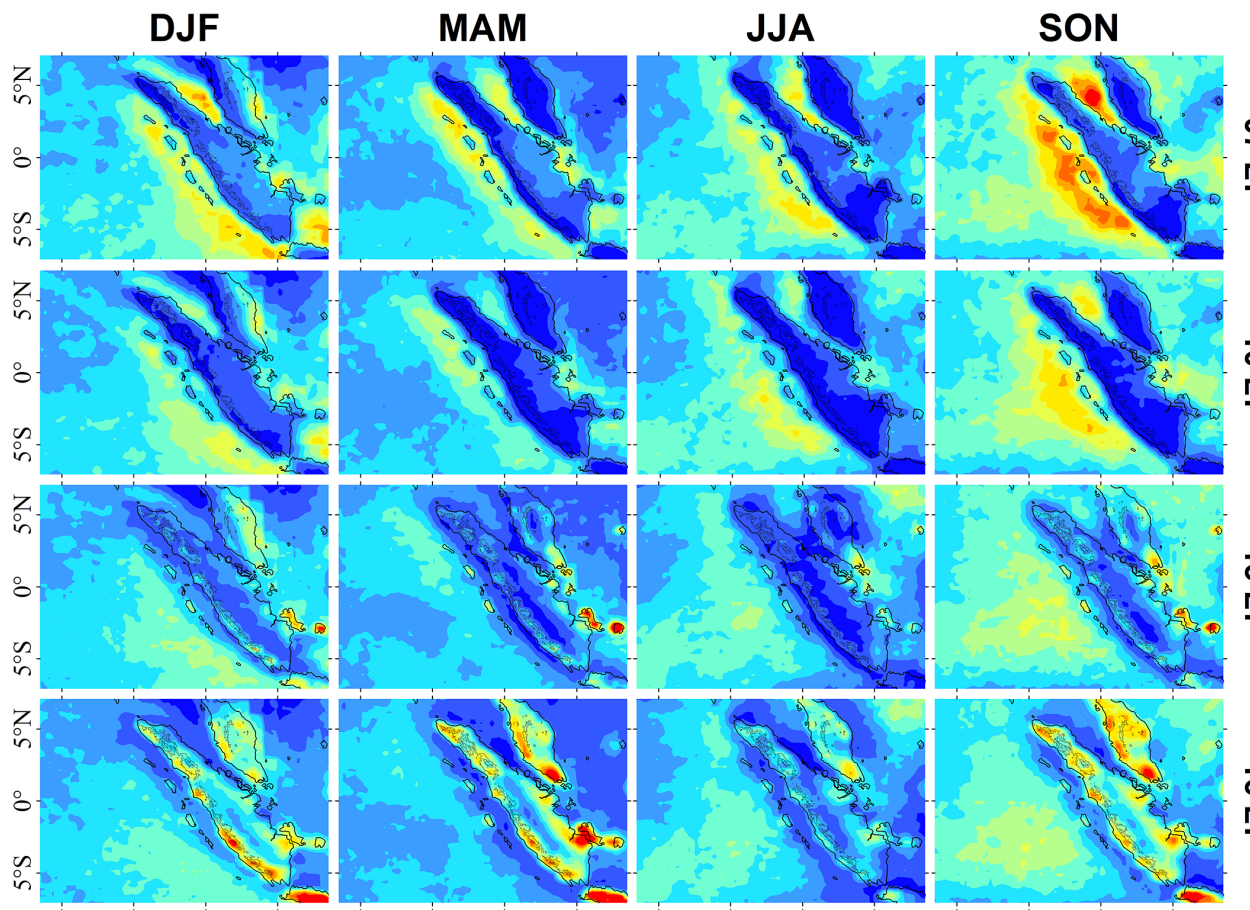

음

\section{$\neg$}
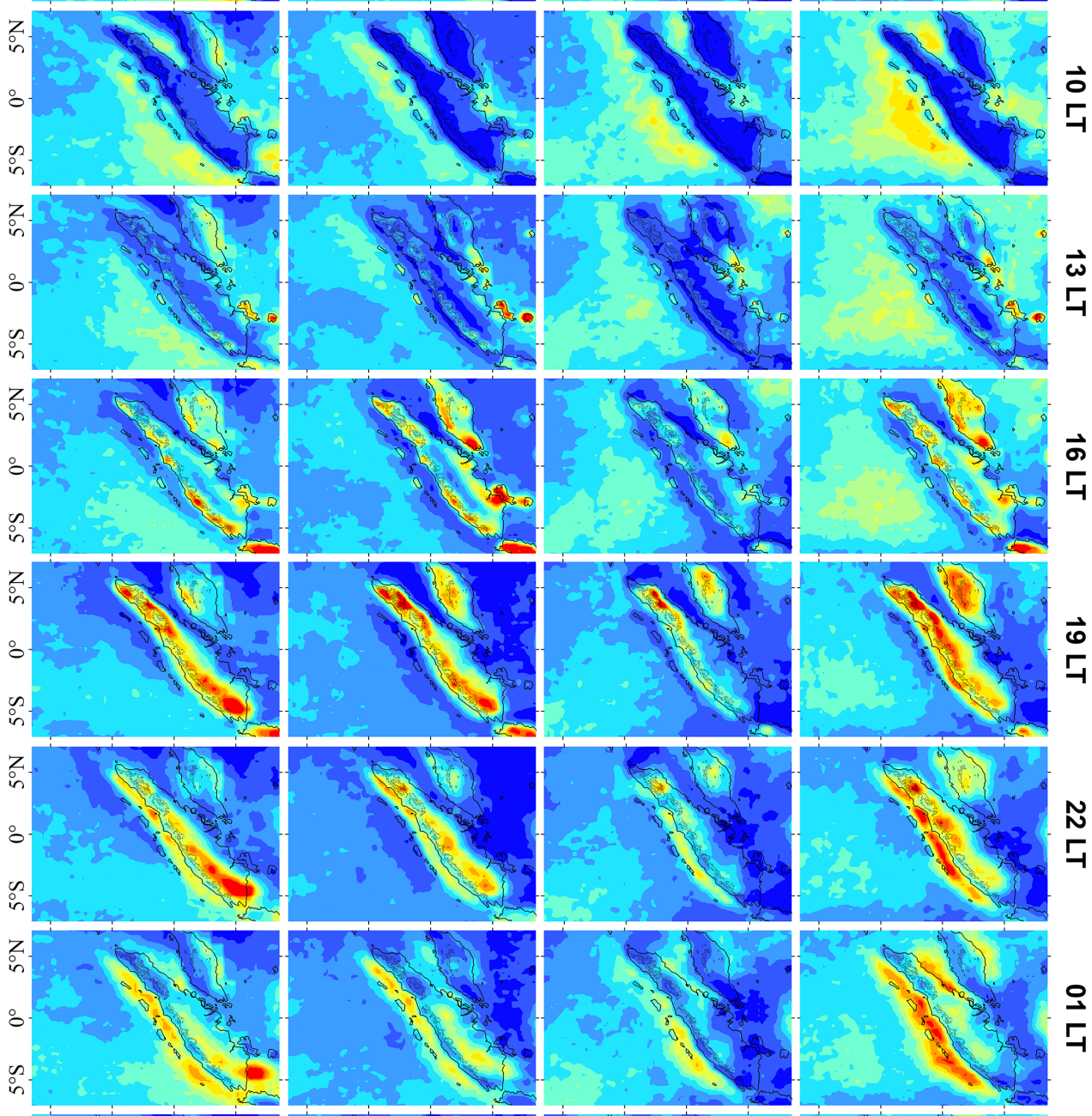

$\stackrel{9}{ }$
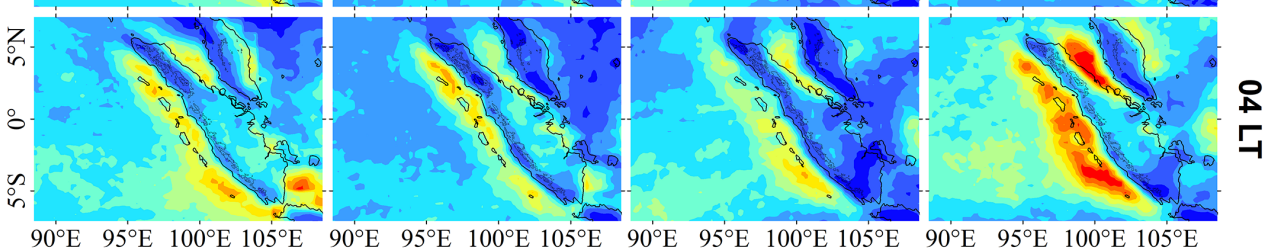

RAINFALL RATE ( $\left.\mathrm{mm} \mathrm{hour}^{-1}\right)$

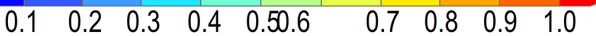

Fig. 2. Seasonally (3-monthly) averaged 17-year (1998-2014) TRMM 3B42 data for a) overall and b) 3-hourly local times. Thick lines denote coastlines, and thin lines denote terrain elevation in $1000-\mathrm{m}$ intervals. 

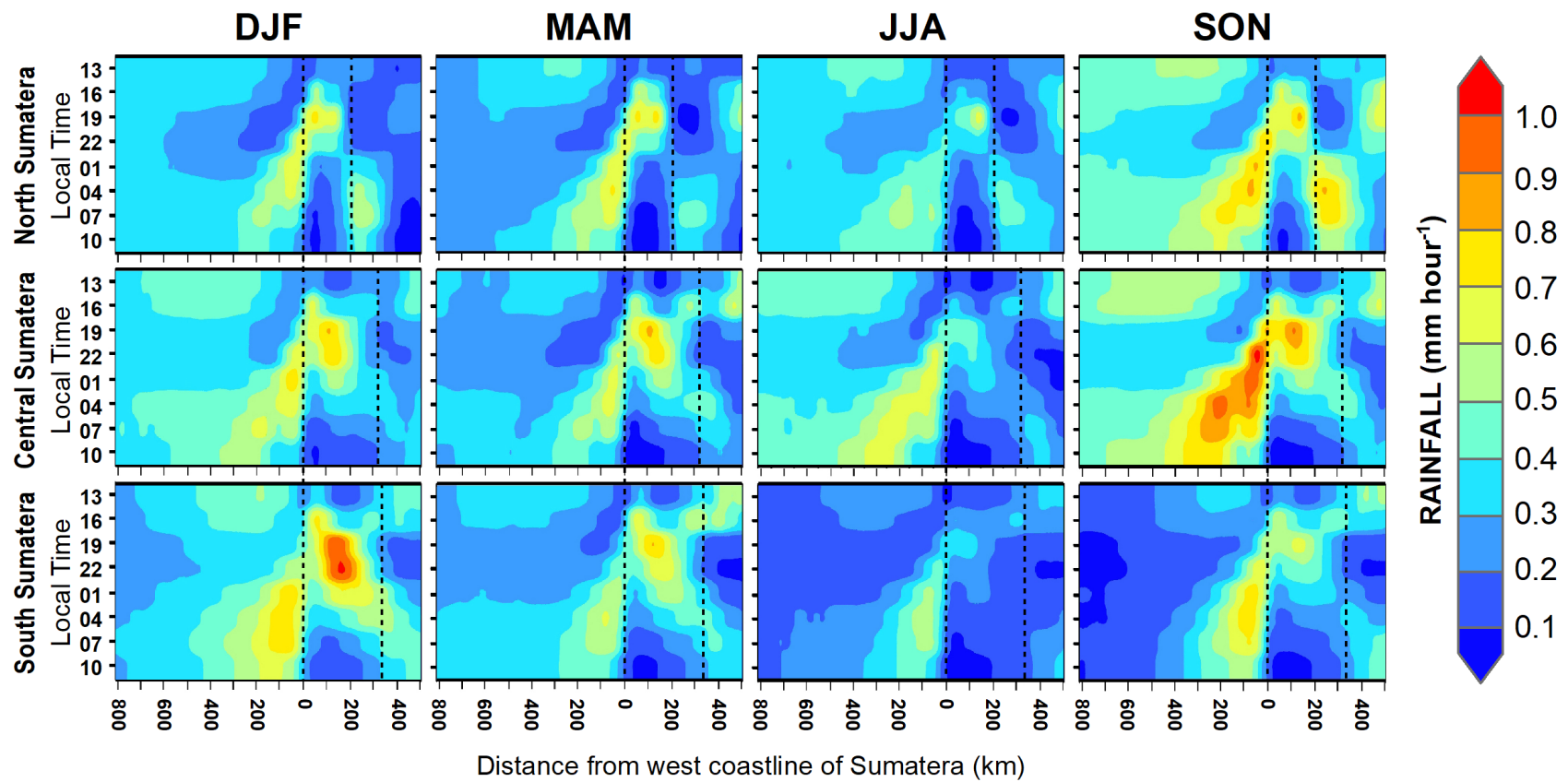

Fig. 3. Hovmöller diagrams for 3-monthly averaged diurnal cycles over the three regions (Boxes I-III in Fig. 1) of the 17-year (1998-2014) TRMM 3B42 rainfall data. Vertical dotted lines represent approximate coastlines (blue lines in Fig. 1) of Sumatera.
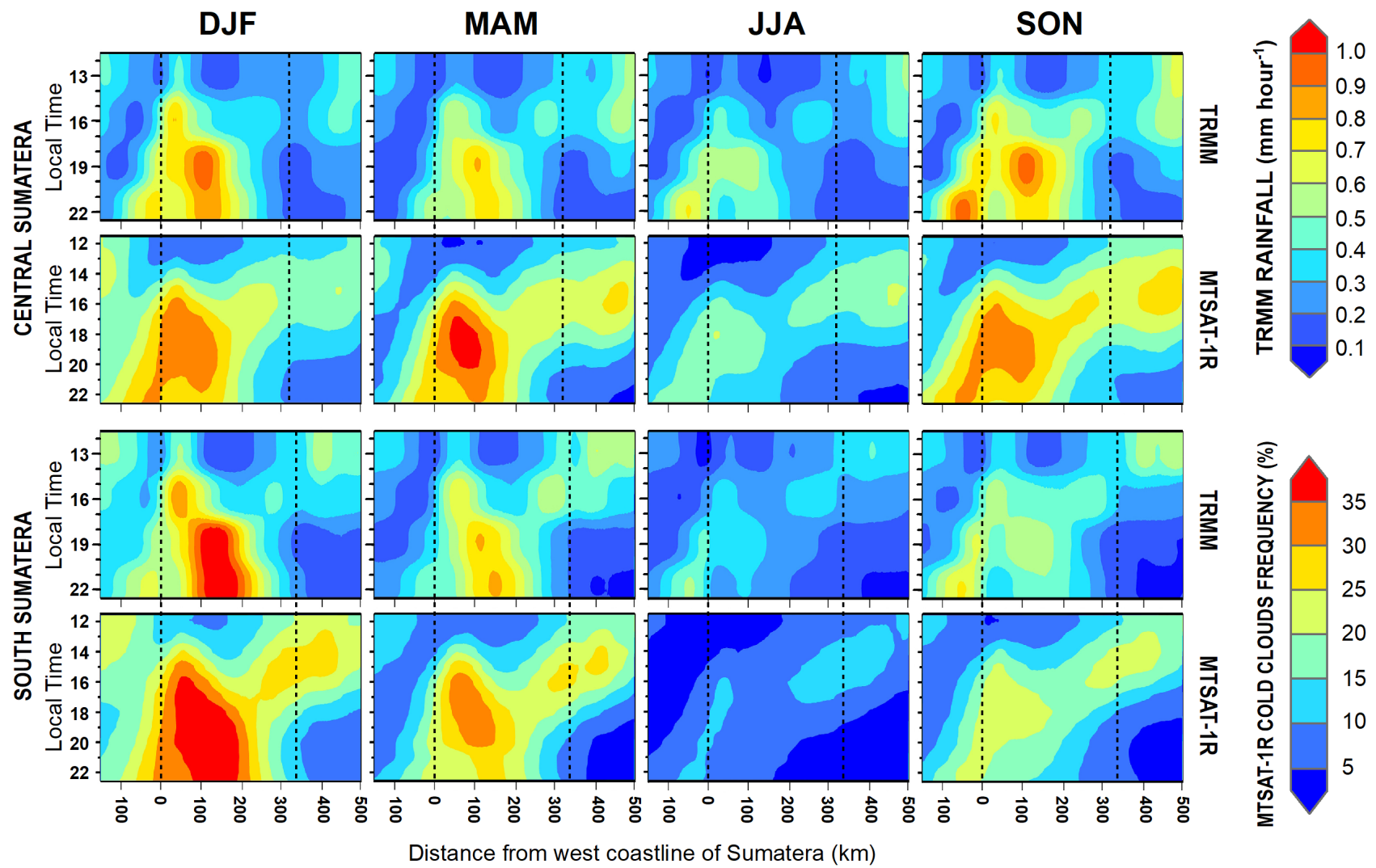

Fig. 4. Hovmöller diagrams for 3-monthly 5-year (July 2005-June 2010) averaged diurnal cycles over the southern and central regions (Boxes II and III in Fig. 1) of rainfall-area migrations from 3-hourly TRMM 3B42 data (upper panels for each region) and tall-cloud frequently-appearing area migrations from hourly MTSAT-1R data (lower panels) analysis. Vertical dotted lines represent approximate coastlines (blue lines in Fig. 1) of Sumatera.

hourly): the tall cloud frequency was enhanced near the east coast of Sumatera (at 300-400-km distance from the coastline) in the early afternoon (at around 13 LT) as shown in Fig. 4.

As shown clearly by MTSAT-1R diagrams (Fig. 4), rainfall peaks at 13 LT in the ECSIs were connected to the Sumatera main island at $16 \mathrm{LT}$, suggesting westward migration toward the inland plains of Sumatera until early evening (about 18 LT) in the central and southern regions (see also Figs. $2 b$ and 3 ). The MTSAT-1R 
could confirm the cloud migration, although the temporal resolution of TRMM 3B42 was not enough to illustrate rainfall area migrations over distances longer than the sizes of the smaller islands. Therefore, there are in total two types of rainfall initiation/ migration in central and southern Sumatera. Features similar to the two types of rainfall/cloud initiation/migration were also seen in Fig. 5 of Mori et al. (2004) via TRMM analysis and in Fig. 4 of Sakurai et al. (2005) in a GMS study, although they mentioned only the westward migration from the Barisan Mountains (for comparison between TRMM and GMS, see, e.g., Imaoka and Nakamura 2012).

Concerning the above-mentioned initiation of DRC, an important condition is considered to be the effect of size (width) of an island. Sobel et al. (2011, a correction in 2013) reported a statistically critical island size $\left(315 \mathrm{~km}^{2}\right)$ for DRC generation over the Indo-Pacific Oceans, including the IMC. Bangka and Belitung Islands have an east-to-west width of $\sim 50-100 \mathrm{~km}$. Mendol Island is smaller but is surrounded by other similar islands. Those small islands are collectively just larger than the critical value needed to generate convective clouds and heavy-rainfall events very quickly at $\sim 13$ LT, which are terminated rapidly and followed by similar events in the central region of the main island of Sumatera in subsequent hours. The northern region of the main island, which has an east-to-west width of $\sim 200 \mathrm{~km}$, slowly develops a rainfall peak in the early evening (19 LT). The southern region ( $\sim 400 \mathrm{~km}$ wide) behaves the same way in late evening (22 LT), especially during DJF and MAM seasons.

There have been studies of DRC over small islands off the west coast of Sumatera (e.g., Wu et al. 2008; Kamimera et al. 2012) and also along a coastal region virtually free from the influence of any small islands (Yokoi et al. 2017). However, the small western islands are much more isolated (by a strait $\sim 100 \mathrm{~km}$ wide) from the main island of Sumatera, and effects of only the latter on the former (such as two rainfall peaks, evening and early morning) have been observed, which is also similar to another case, for a small island off the north coast of Papua (Tabata et al. 2011). The effect of a neighboring large island (westward migration of DRC on the west coast of Kalimantan; e.g., Shibagaki et al. 2006) may contribute to the pattern of DRC in the ECSIs, but may be out of the scope of this paper focused on Sumatera.

\subsection{Seasonal differences in eastward and westward diurnal rain- fall migrations}

As shown in Fig. 3, the clearest migration pattern in the eastward direction occurs during DJF in the southern region, while in the westward direction such a pattern appears during SON in the central region. During JJA, the eastward migration in the northern region is clearer than in the central region, while eastward migration is virtually nonexistent in the southern region. These are consistent with results obtained by Sakurai et al. (2005) that illustrated the eastward rainfall migration appears only when the dominant low-level tropospheric wind is westerly, which occurs with the ITCZ. Another seasonally hemispheric asymmetry of the Asia-Australia monsoon (Chang et al. 2005) may be responsible for the difference in the appearance, speed, and distance of the westward and eastward migrations of DRC systems. We analyzed these rainfall systems by using much longer-term TRMM 3B42 data and found that they are basically similar to those in the 3-year discontinuous TRMM PR data reported by Mori et al. (2004) and the cloud system features from the 1-year GMS blackbodytemperature data reported by Sakurai et al. (2005).

The westward-migration distances (e.g., $\sim 700 \mathrm{~km}$ in SON and $\sim 200 \mathrm{~km}$ in MAM for the central region, and $\sim 350 \mathrm{~km}$ in DJF for the southern region) are consistent with the scale (i.e., hundreds of $\mathrm{km}$ ) of rainfall concentration near the coastline described by Ogino et al. (2016) based on annual-mean analysis of TRMM PR data. Yamanaka et al. (2018) also show that regional rainfall is a function of the coastline length divided by the land area. However, they do not mention seasonal differences in coastal-rainfall concentration. Our study further revealed that the horizontal scale of coastal-rainfall concentration varies seasonally and meridionally.

Several mechanisms that may influence rainfall/cloud initia- tion/migration have been proposed and investigated in previous studies. Mori et al. (2004) proposed that in the early afternoon, along the west coast of Sumatera Island, initial convection is triggered when the sea breeze encounters the mountain range. Several studies (e.g., Yang and Slingo 2001; Mori et al. 2004; Ichikawa and Yasunari 2006; Yanase et al. 2017) suggested that the possible mechanisms of offshore migration are the advection process associated with background wind and/or the interaction between a gravity current and an ambient wind, which can trigger the self-replication of convective systems. Gravity waves due to strong diurnal signals over coastal land are also an important mechanism for the offshore migration of rainfall around midnight over Sumatera (Yokoi et al. 2017), and their propagation is highly dependent on and interacts with background wind that varies seasonally with monsoons (Yanase et al. 2017). The interaction between these mechanisms and the seasonal existence of the ITCZ can provide different favorable conditions for rainfall migration in each season. To study these mechanisms it is necessary to analyze also temperature, humidity and wind based on objective analysis data.

\section{Acknowledgments}

The lead author (ARA) was supported by the RONPAKU (Dissertation PhD) Program of Japan Society for the Promotion of Science (JSPS). For the TRMM 3B42 v7 data we gratefully acknowledge the National Aeronautics and Space Administration (NASA) and the Japan Aerospace Exploration Agency (JAXA). MTSAT-1R data were used through the courtesy of Japan Meteorological Agency (JMA), Weathernews Inc., Earthquake Research Institute and Institute of Industrial Science (W. Takeuchi Lab.) of the University of Tokyo, and Center for Environmental Remote Sensing (CeRES) of Chiba University. Thanks are extended to Dr. S. Mori of the Japan Agency for Marine-Earth Science and Technology (JAMSTEC), two Editors (Prof. A. Manda and Dr. S.-Y. Ogino) and four anonymous reviewers for their valuable suggestions and constructive comments.

Edited by: S. Ogino

\section{References}

Aldrian, E., and R. D. Susanto, 2003: Identification of three dominant rainfall regions within Indonesia and their relationship to sea surface temperature. Int. J. Climatol., 23, 1435-1452.

As-syakur, A. R., T. Osawa, F. Miura, I. W. Nuarsa, N. W. Ekayanti, I. G. B. S. Dharma, I. W. S. Adnyana, I. W. Arthana, and T. Tanaka, 2016: Maritime Continent rainfall variability during the TRMM era: the role of monsoon, topography and El Niño Modoki. Dyn. Atmos. Oceans, 75, 58-77.

Chang, C.-P., Z. Wang, J. McBride, and C.-H. Liu, 2005: Annual cycle of Southeast Asia-Maritime Continent rainfall and the asymmetric monsoon transition. J. Climate, 18, 287-301.

Fujita, M., F. Kimura, and M. Yoshizaki, 2010: Morning precipitation peak over the Strait of Malacca under a calm condition. Mon. Wea. Rev., 138, 1474-1486.

Hamada, J.-I., M. D. Yamanaka, J. Matsumoto, S. Fukao, P. A. Winarso, and T. Sribimawati, 2002: Spatial and temporal variations of the rainy season over Indonesia and their link to ENSO. J. Meteor. Soc. Japan, 80, 285-310.

Hirose, M., R. Oki, S. Shimizu, M. Kachi, and T. Higashiuwatoko, 2008: Finescale diurnal rainfall statistics refined from eight years of TRMM PR data. J. Appl. Meteor. Climatol., 47, 544-561.

Huffman, G. J., R. F. Adler, D. T. Bolvin, G. Gu, E. J. Nelkin, K. P. Bowman, Y. Hong, E. F. Stocker, and D. B. Wolff, 2007: The TRMM multisatellite precipitation analysis (TMPA): Quasi-global, multiyear, combined-sensor precipitation estimates at fine scales. J. Hydrometeor., 8, 38-55.

Ichikawa, H., and T. Yasunari, 2006: Time-space characteristics 
of diurnal rainfall over Borneo and surrounding oceans as observed by TRMM-PR. J. Climate, 19, 1238-1260.

Imaoka, K., and K. Nakamura, 2012: Statistical analysis of the life cycle of isolated tropical cold cloud systems using MTSATIR and TRMM Data. Mon. Wea. Rev., 140, 3552-3572.

Kamimera, H., S. Mori, M. D. Yamanaka, and F. Syamsudin, 2012: Modulation of diurnal rainfall cycle by the MaddenJulian oscillation based on one-year continuous observation with a meteorological radar in west Sumatera. SOLA, 8 , $111-114$.

Matsumoto, J., B. Wang, G.-X. Wu, J.-P. Li, P.-M. Wu, M. Hattori, S. Mori, M. D. Yamanaka, Hamada J.-I., F. Syamsudin, T. Koike, K. Tamagawa, E. Ikoma, H. Kinutani, H. Kamahori, K. Kamiguchi, and Y. Harada, 2017: An overview of the Asian Monsoon Years 2007-2012 (AMY) and multi-scale interactions in the extreme rainfall events over the Indonesian maritime continent. The Global Monsoon System: Research and Forecast, 3rd Ed., C.-P. Chang, H.-C. Kuo, N.-C. Lau, R. H. Johnson, B. Wang, and M. C. Wheeler, Eds., World Scientific Series on Asia-Pacific Weather and Climate: Vol. 9, World Scientific Publication Company, 365-386.

Murakami, T., and J. Matsumoto, 1994: Summer monsoon over the Asian continent and western North Pacific. J. Meteor. Soc. Japan, 72, 719-745.

Mori, S., J.-I. Hamada, Y. I. Tauhid, M. D. Yamanaka, N. Okamoto, F. Murata, N. Sakurai, H. Hashiguchi, and T. Sribimawati, 2004: Diurnal land-sea rainfall peak migration over Sumatera Island, Indonesian Maritime Continent, observed by TRMM satellite and intensive rawinsonde soundings. Mon. Wea. Rev., 132, 2021-2039.

Ogino, S.-Y., M. D. Yamanaka, S. Mori, and J. Matsumoto, 2016: How much is the precipitation amount over the tropical coastal region? J. Climate, 29, 1231-1236.

Sakurai, N., F. Murata, M. D. Yamanaka, S. Mori, J. Hamada, H. Hashiguchi, Y. I. Tauhid, T. Sribimawati, and B. Suhardi, 2005: Diurnal cycle of cloud system migration over Sumatera Island. J. Meteor. Soc. Japan, 83, 835-850.

Shibagaki, Y., T. Shimomai, T. Kozu, S. Mori, Y. Fujiyoshi, H. Hashiguchi, M. K. Yamamoto, S. Fukao, and M. D. Yamanaka, 2006: Multiscale aspects of convective systems associated with an intraseasonal oscillation over the Indonesian maritime continent. Mon. Wea. Rev., 134, 1682-1696.

Sobel, A. H., C. D. Burleyson, and S. E. Yuter, 2011: Rain on small tropical islands. J. Geophys. Res. Atmos., 116, D08102.
Sobel, A. H., C. D. Burleyson, S. E. Yuter, and M. Biasutti. 2013: Correction to "Rain on small tropical islands". J. Geophys. Res. Atmos., 118, 2301-2302.

Tabata, Y., H. Hashiguchi, M. K. Yamamoto, M. Yamamoto, M. D. Yamanaka, S. Mori, F. Syamsudin, and T. Manik, 2011: Observational study on diurnal precipitation cycle in equatorial Indonesia using 1.3-GHz wind profiling radar network and TRMM precipitation radar. J. Atmos. Solar Terr. Phys., 73, 1031-1042.

Takahashi, H. G., 2016: Seasonal and diurnal variations in rainfall characteristics over the tropical Asian monsoon region using TRMM-PR data. SOLA, 12A, 22-27.

Wang, B., R. Wu, and T. Li, 2003: Atmosphere-warm ocean interaction and its impacts on Asian-Australian monsoon variation. J. Climate, 16, 1195-1211.

Wu, P.-M., M. Hara, J.-I. Hamada, M. D. Yamanaka, and F. Kimura, 2009: Why a large amount of rain falls over the sea in the vicinity of western Sumatra Island during nighttime. $J$. Appl. Meteor. Climatol., 48, 1345-1361.

Wu, P.-M., S. Mori, Hamada J.-I., M. D. Yamanaka, J. Matsumoto, and F. Kimura, 2008: Diurnal variation of rainfall and precipitable water over Siberut Island off the western coast of Sumatera Island. SOLA, 4, 125-128.

Yamanaka, M. D., 2016: Physical climatology of Indonesian maritime continent: An outline to comprehend observational studies. Atmos. Res., 178, 231-259.

Yamanaka, M. D., S.-Y. Ogino, P. M. Wu, J.-I. Hamada, S. Mori, J. Matsumoto, and F. Syamsudin, 2018: Maritime continent coastlines controlling Earth's climate. Prog. Earth Planet. Sci. $\mathbf{5}, 21$.

Yanase, A., K. Yasunaga, and H. Masunaga, 2017: Relationship between the direction of diurnal rainfall migration and the ambient wind over the Southern Sumatra Island. Earth Space Sci., 4, 117-127.

Yang, G.-Y., and J. Slingo, 2001: The diurnal cycle in the Tropics. Mon. Wea. Rev., 129, 784-801.

Yokoi, S., S. Mori, M. Katsumata, B. Geng, K. Yasunaga, F. Syamsudin, Nurhayati, and K. Yoneyama, 2017: Diurnal cycle of precipitation observed in the western coastal area of Sumatra Island: offshore preconditioning by gravity waves. Mon. Wea. Rev., 145, 3745-3761.

Manuscript received 20 July 2019, accepted 11 September 2019

SOLA: https://www.jstage.jst.go.jp/browse/solal 